\title{
Business success of an environmental organization
}

\author{
Dmitry Trukhanov ${ }^{1, *}$ and Gennadiy Pryakhin ${ }^{1}$ \\ ${ }^{1}$ Chelyabinsk State University, 129, Kashirin Brothers str., 454001, Chelyabinsk, Russia
}

\begin{abstract}
The article explores new approaches to assessing and determining the business success of the subject of economic activity. time factor. It should be noted that Russian and foreign authors characterize the concept of business success and methods of its evaluation in different ways, on the basis of which we have adopted an attempt to consciousness of a completely new approach to this issue. The paper provides examples based on the financial statements of the two major organizations in Chelyabinsk, showing the parallel between our theoretical assumptions based on economic and mathematical methods and existing factors of the internal and external environment. The authors note that this article was prepared in connection with the weak development of researchers earlier on this issue from the position of economic and mathematical methods and existing theories of other exact sciences. For example, the study of organizations using bifurcation theory is almost entirely absent in modern literature and scientific publications. This work will clarify the definition of business success and explore new approaches to its assessment
\end{abstract}

\section{Introduction}

Business success is quite a broad category, which was investigated by Russian and foreign authors [11]. Different authors express different opinions about the definition of business success and, accordingly, the nature of research is quite spontaneous, has no structure and is not considered from different sides and horizons of the economy.

A number of authors [3] approaches to assessing business success on the part of financial indicators. He singles out almost all existing indicators as an assessment of the success of activities, including liquidity, turnover, profitability, market value, return on investment, correctness of risk analysis, sensitivity analysis. Authors, in an article on mathematical models of risk assessment, writes that the main purpose of applying mathematical modeling in risk assessment is to describe the overall model: $\mathrm{R} \mathrm{q} \mathrm{f}(\mathrm{P}, \mathrm{I})$, where $\mathrm{P}$ is the probability of a risky event, I is the influence of factors [5]. Mathematical methods of market analysis by I.K. Burmistrova are divided into general scientific, analytical and predictive, planned methods.that is, it operates within the original rules of the game [12]. This leads to the fact that mathematical methods are limited in economics when studying business success. I.K. Burmistrova considers the criteria of Wald, Hurwitz, which weighs optimistic and pessimistic situations, as well as a number of other methods for assessing uncertain (fuzzy) factors. We

${ }^{*}$ Corresponding author: R4comm@yandex.ru 
note to all of these that the problem is posed not only in the area of uncertainty about the concept of business success of the organization, but also in the area of different approaches of authors to study this problem.

\section{Materials and methods}

The methodology is based on a comparison of economic and mathematical methods in economics, as well as a cognitive map of business success. This comparison greatly complements existing methods for assessing business success in the study of economic actors. The main difficulty was in selecting sources and methods of work that would ensure the reliability of the data received and help to obtain reliable conclusions [6]. We have researched scientific literary terms about many and their connections, as well as scientific publications on the theory of bifurcation.

\section{Results}

Looking at the study of bifurcation theory and cognitive maps in detail, we found practical evidence that by researching the organization using bifurcation theory and operating on the presence of a time indicator. In this way, we introduce the time factor into the external and significant factor influencing the business success of the organization. We believe that one of the features of time is the fundamental impossibility of re-presenting one moment of time for verification measurements and observations, which makes different authors have different understandings of business success. Using methods from sections of higher mathematics, namely cognitive maps and bifurcation theory, we calculate and graphically prove the fact that the time factor is the most important factor influencing the business success of the organization. These findings provide a new assessment of mathematical approaches to the study and evaluation of business success, as well as demonstrate the importance of multilateral study of this issue [9].

The first approach we offer to research business success is cognitive maps, where expert assessments can assess the impact of groups of factors and factors on business success. Note that all existing cognitive maps do not have a time area that reflects the dynamic change of the system, however, based on the article Haoming zhong, Chunyan Miao, zhiqi Shen, Yuhong Feng on temporary cognitive maps, we will divide the cognitive map of the organization into three parts - macro-indicators, micro-indicators and cause-and-effect communications [2]. Macro-indicators have simple structures, their condition is solved only by environmental inputs.

To make the map, we used a combination of macro-meso-micro-micro-level of the organization's environment, as well as their combination with existing socio-environmental and economic factors. The article on the study of the environmental, social and economic problems of the regions at the UN summit (New York, 2015) proposed the approach of a comprehensive assessment of regions using these factors. Also socio-environmentaleconomic approach to the evaluation of the development of the subject of economic activity was proposed by any authors [4].

The second approach to the study of business success we consider the theory of bifurcation. Unlike classical methods of analysis, bifurcation theory allows to distinguish jump transitions of the system from one state to another. That is to distinguish the period of sharp rise from stagnation. This theory was studied by the author [8]. However, to date, there is an almost complete lack of methodology for assessing business success, based on the theory of bifurcation, despite the fundamental results and research of the theory of bifurcation laid by Poincare, Andronov, Whitney. The theory of bifurcation analyzes the critical points 
(rehearsals) of the potential function, that is, the points where not only the first derivative of the function is zero, but also zero are the same derivatives of a higher order. In other words, this section of mathematics examines the moment the system transitions from stable to unstable [1].

We can apply the bifurcation theory to the study of business success, allowing us to assess the potential of the organization, which is sufficient to change the system in both directions.

The concepts of the cognitive development map of Modern Stone LLC are presented in Table 1 "Modern Stone Cognitive Map Concepts." Concepts are broken down into macromeso and micro-levels.

Table 1. "Modern Stone Cognitive Map Concepts" (Compiled by the authors).

\begin{tabular}{|c|c|}
\hline Level & Concept \\
\hline \multirow{6}{*}{ Macro level } & Demand \\
\hline & Offer \\
\hline & Depth of marketing research \\
\hline & Territorial location \\
\hline & The region's investment appeal \\
\hline & Market capacity \\
\hline \multirow{9}{*}{ Meso-level } & Assets \\
\hline & Revolving capital \\
\hline & Operating profit \\
\hline & Revenue \\
\hline & Level of satisfaction with your work \\
\hline & Compliance with the system $5 \mathrm{~s}-1$ \\
\hline & Costs \\
\hline & Production load \\
\hline & Profitability \\
\hline \multirow{5}{*}{ Micro-level } & Management's level of knowledge \\
\hline & $\begin{array}{l}\text { The extent of the imbalance in the interests of domestic } \\
\text { stakeholders }\end{array}$ \\
\hline & Staff quality \\
\hline & The ability to correctly perceive facts \\
\hline & Definin \\
\hline
\end{tabular}

MODERN STONE LLC has been operating since 2013. The organization's business is the production of building materials. This enterprise has passed the stage of origin and formation. One way to take into account the variety of factors and their impact in the enterprise is a cognitive map.

Deciphering the relationships reflected on the cognitive map is presented in Table 2. The effect will be marked by values from -1 (strong negative effect) to 1 (strong positive effect).

Table 2. Entrances, exits, tops impact (Compiled by the authors).

\begin{tabular}{|c|c|c|c|}
\hline № & Vertex & Entrance & Output \\
\hline 1 & Demand & $4(0.5) .5(0.2)$. & $2(0.5) .10(0.2)$ \\
\hline 2 & Offer & $1(0.5) .3(0.2) .6(0.5)$ & $10(0.2)$ \\
\hline 3 & Depth of marketing research & $16(0.5)$ & $2(0.5) .4(0.2) .15(0.2)$ \\
\hline 4 & Territorial location & $3(0.5) .7(0.0 .2)$ & $1(0.5) .10(0.2)$. \\
\hline 5 & The region's investment appeal & $5(0.5) .3(0.2) .6(0.5)$ & $1(0.2)$ \\
\hline 6 & Market capacity & $2(0.5) .5(0.2)$. & $2(0.5) .5(0.2)$ \\
\hline & & - & $8(0.5) .9(0.5) .10(0.5)$. \\
7 & Assets & & $13(-0.5) .14(0.5) .15$ \\
& & & $(0.5)$ \\
\hline \multirow{2}{*}{8} & Revolving capital & $7(0.5) .9(0.5) .10(0.5)$. & $7(0.5) .9(0.5) .10(0.5)$. \\
& & $13(-0.5) .15(0.5)$ & $13(-0.5) .15(0.5)$ \\
\hline
\end{tabular}




\begin{tabular}{|c|c|c|c|}
\hline 9 & Operating profit & $\begin{array}{c}7(0.5) .8(0.5) .10(0.5) . \\
13(-0.5) .15(0.5)\end{array}$ & $\begin{array}{c}7(0.5) .8(0.5) .10(0.5) . \\
13(-0.5) .15(0.5)\end{array}$ \\
\hline 10 & Revenue & $\begin{array}{c}7(0.5) .8(0.5) .9(0.5) .13 \\
(-0.5) .15(0.5)\end{array}$ & $\begin{array}{c}7(0.5) .8(0.5) .9(0.5) . \\
13(-0.5) .15(0.5)\end{array}$ \\
\hline 11 & $\begin{array}{c}\text { Level of satisfaction with your } \\
\text { work }\end{array}$ & - & - \\
\hline 12 & $\begin{array}{c}\text { Compliance with the system } \\
5 \text { s-1 }\end{array}$ & - & $8(0.5) .9(0.5) .10(1)$. \\
13 & Costs & $8(0.3) .15(1)$ & $8(1) .10(0.5)$ \\
\hline 14 & Production load & $1(1) .7(1)$ & $3(1) .13(0.5)$ \\
\hline 15 & Profitability & $13(1)$ & - \\
\hline 16 & $\begin{array}{c}\text { Management's level of } \\
\text { knowledge }\end{array}$ & $19(0.3)$ & $13(1) .14(0.8)$ \\
\hline 17 & $\begin{array}{c}\text { The extent of the imbalance in } \\
\text { the interests of domestic } \\
\text { stakeholders }\end{array}$ & - & $16(0.3)$ \\
\hline 18 & $\begin{array}{c}\text { The correctness of the chosen } \\
\text { team }\end{array}$ & - & - \\
\hline 19 & $\begin{array}{c}\text { The ability to correctly } \\
\text { perceive facts }\end{array}$ & - & - \\
\hline 20 & $\begin{array}{c}\text { Defining and following your } \\
\text { goals }\end{array}$ & - & $-10.5)$ \\
\hline
\end{tabular}

The "entry" column shows incoming streams in a particular concept of a cognitive map, numbers the intensity of the flow in the interval from "-1; 1 ". With the sign "-" negative influences on the concept, with the sign of " $\mathrm{z}$ " positive influences on the concept. Accordingly, the "exit" column reflects the streams coming out of the concept and their intensity.

Thus, a cognitive map for Modern Stone LLC was built, reflecting the intensity of the interaction of the development factors of the organization.

Below is a general view of the Altman model:

$$
\mathrm{Z}=1.2 * \mathrm{X}_{1}+1.4 * \mathrm{X}_{2}+3.3 * \mathrm{X}_{3}+0.6 * \mathrm{X}_{4}+\mathrm{X}_{5}
$$

Where is:

$\mathrm{X}_{1}$ - Revolving capital/assets;

$\mathrm{X}_{2}$ - Undistributed Profit/Assets;

$\mathrm{X}_{3}$ - Operating Profit/Assets;

$\mathrm{X}_{4}$ - Market Value of Shares/Commitments";

$\mathrm{X}_{5}$ - Revenue/Assets, q- the sustainability of the organization.

If it's a financial sustainability zone.

If 1.8 qlt; zlt;2.9 is a zone of uncertainty;

If it is a financial risk zone.

However, Modern Stone LLC does not issue securities, so we use the Altman model for companies whose shares are not traded on the stock market.

$$
\mathrm{Z}=0.717 * \mathrm{X}_{1}+0.847 * \mathrm{X}_{2}+3.107 * \mathrm{X}_{3}+0.420 * \mathrm{X}_{4}+0.988 \mathrm{X}_{5}
$$

We calculate the financial stability of the company at the start-up stage. Having the financial data of the organization, we calculate, based on deciphering the formula 1 value of unknown variables.

$$
\begin{gathered}
Z=0.717 * \frac{1}{3}+0.847 * \frac{1}{12}+3.107 * \frac{1}{24}+0.420 * 1+0.988 * \frac{1}{12} \\
Z=0.3585+0.1058+0.19418+0.420+0.1235
\end{gathered}
$$




$$
\mathrm{Z}=1.201 \text {. }
$$

Based on the calculations made by Modern Stone LLC at the birth stage was in the bankruptcy zone.

We've removed all related items that are not part of the Altman model. In working capital, the amount of outgoing flows is equal to the amount of incoming, as well as in operating profit and revenue. The field in table 1 of the incoming assets in the cognitive map is empty. This is due to the fact that at the beginning of the enterprise, the assets are formed from the founder's own funds, and working capital is directed to the purchase of raw materials for production [13]. Therefore, the total outgoing flow is 1.5. Consider this in Altman's model:

$$
\begin{gathered}
\mathrm{Z}=0.717 * \frac{1}{3}+0.847 * \frac{1}{12}+3.107 * \frac{1}{24}+0.420 * 1+0.988 * \frac{1}{12} \\
Z=0.239+0.0705+1.294+0.420+0.082 \\
Z=2.1
\end{gathered}
$$

In connection with the foregoing, we can draw the first conclusion that Modern Stone LLC was in the zone of uncertainty at the stage of origin. Therefore, it should be noted that there is a difference in calculations. In the first case the organization is in bankruptcy, in the second in uncertainty. This is due to the level of detail of the calculations.

As stated at the beginning of the article, we can explore business success with the theory of bifurcation, which can be graphically depicted in Figure 1.

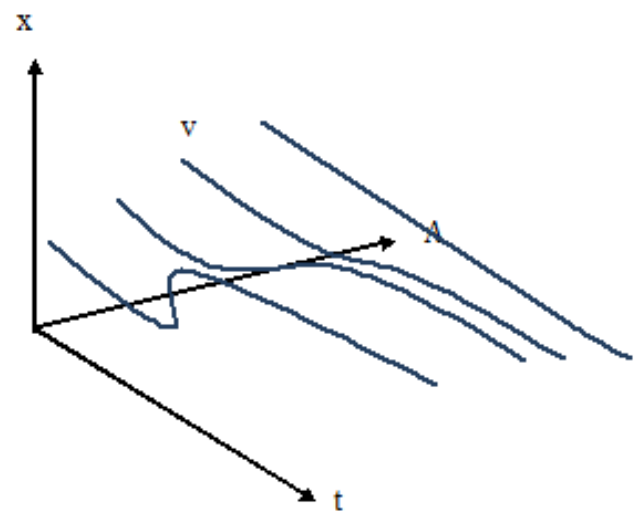

Fig. 1. Graphic Interpretation of Business Success Acquisition.

In Figure 1, the line $\mathrm{v}$ curve is a line of business success that changes when you change parameters $\mathrm{A}, \mathrm{x}, \mathrm{t}$, where:

$\mathrm{x}=\mathrm{f}\left(\mathrm{x}_{1}, \mathrm{x}_{2}, \mathrm{x}_{3}, \mathrm{x}_{4}, \mathrm{x}_{5}\right)$ five factors of the Altman model;

$A=f\left(y_{1}, y_{2}\right)$, where $y_{1}$ The number of redundancies $y_{2}$ Profitability

t- time.

We use a "assembly" disaster from bifurcation theory. This type is used when we have one parameter that affects the crisis of the enterprise:

$$
\mathrm{v}=\frac{1}{4} \mathrm{x}^{4}+\frac{1}{2} \mathrm{Ax} \mathrm{x}^{2}+\mathrm{tx}
$$

Above, we looked at the Construction of the Altman model for Modern Stone LLC, which, depending on the cognitive map, changes the value of the Altman coefficient from 1.201 to 2.1. Let's look at how this change will affect the graphic interpretation of bifurcation theory. 
Let's take the $\mathrm{X}$ value equal to 1.201 , then:

$$
\begin{aligned}
& \mathrm{v}=\frac{1}{4} 1.201^{4}+\frac{1}{2} 1 * 1.201^{2}+\mathrm{tx} \\
& \mathrm{v}=0.5201+1.4424+\mathrm{t} 1.201 ;
\end{aligned}
$$

vq 1.201t q 1,9625 at K Altman 1.201.

If the Altman coefficient is 2.1, then:

$$
\begin{gathered}
\mathrm{v}=\frac{1}{4} 2.1^{4}+\frac{1}{2} 1^{2} 2.1^{2}+\mathrm{t} 2.1 ; \\
\mathrm{v}=4.8620+2.205+\mathrm{t} 2.1 ; \\
\mathrm{v}=2.1 \mathrm{t}+7.067 .
\end{gathered}
$$

Graphically, the direct data looks like Figure 2:

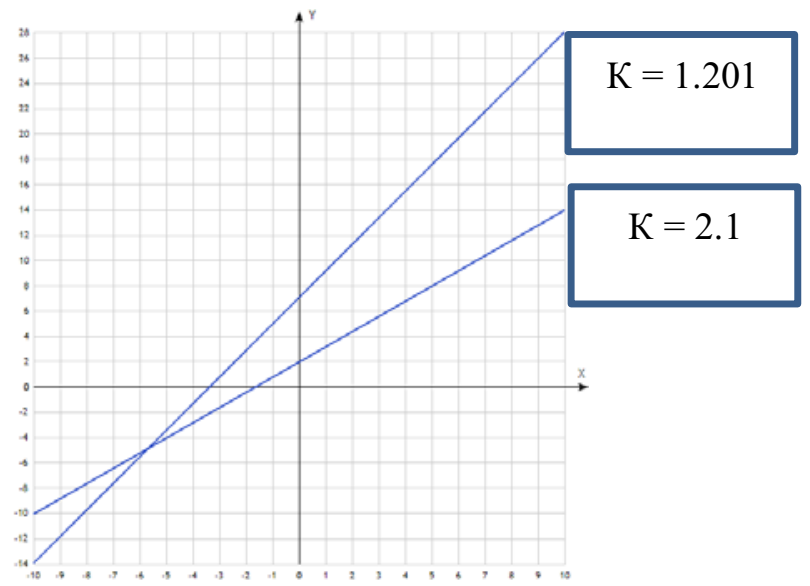

Fig. 2. Curves at different values of the Altman coefficient. Compiled by the author.

We will call this situation parametric bifurcation, that is, when the number of variables changes, there is a jump change in the system. The graph shows how the direct area changes if we look at the Altman coefficient without a cognitive map and with it. Let's go back to the basic theory of bifurcation - a disaster of the type of assembly.

$$
\mathrm{v}=\frac{1}{4} \mathrm{x}^{4}+\frac{1}{2} \mathrm{ax}^{2}+\mathrm{bx}
$$

In our case, the v curve will have the appearance of:

$$
\begin{aligned}
& \text { 1. } \mathrm{v}=\frac{1}{4} \mathrm{t}^{4}+\frac{1}{2} \mathrm{at}^{2}+\mathrm{zt} \\
& \text { 2. } \mathrm{v}=\frac{1}{4} \mathrm{a}^{4}+\frac{1}{2} \mathrm{ta}^{2}+\mathrm{za} \\
& \text { 3. } \mathrm{v}=\frac{1}{4} \mathrm{a}^{4}+\frac{1}{2} \mathrm{zx}^{2}+\mathrm{ta} \\
& \text { 4. } \mathrm{v}=\frac{1}{4} \mathrm{x}^{4}+\frac{1}{2} \mathrm{ax}^{2}+\mathrm{zx}
\end{aligned}
$$

Depending on the $\mathrm{x}$ option (from the basic formula), in our case, where $\mathrm{x}$ is the time $\mathrm{t}$ (since the basic build is unfolding under our axis), we cannot take Formula 1 because time is determinant. Because it's rice. 2 time is linear for our display, we need to take formula 3 , 
because it has a linear display of time and determining parameters, which are the selected coefficients.

The function is defined by $z$.

$$
\begin{gathered}
Z=-2 . v=\frac{1}{4} y^{4}-x+t y \\
Z=-1 . v=\frac{1}{4} y^{4}-\frac{1}{2} x^{2}+t y \\
Z=0 . v=\frac{1}{4} y^{4}+t y \\
Z=1 . v=\frac{1}{4} y^{4}+\frac{1}{2} x^{2}+t y \\
Z=2 . v=\frac{1}{4} y^{4}+\frac{1}{2} x^{2}+t y \\
Z=3 . v=\frac{1}{4} y^{4}+1,5 x^{2}+t y
\end{gathered}
$$

The value of the function increases at $z^{\prime} g t ; 0$ and decreases at $z$ z'lt.0. Function behavior is determined by the amount of profitability (q). However, if we consider an average annual roicer of $40 \%$, i.e. 0.4 , the graphical function looks like point:

Behavior v at z q 0.4 (organization sustainability curve at profitability of 0.4 )

However, when considering the profitability in the winter of the organization for the production of building materials in the Chelyabinsk region of "Modern Stone" LLC at z q 0, the schedule changes dramatically like 2-line.

Behavior $\mathrm{v}$ at $\mathrm{z}$ q 0 . (the organization's sustainability curve at a profitability of 0.4 )

Thus, as a second conclusion, we can also see some ambivalence in calculating disaster and achieving business success. Thus, based on their calculations, the business success of the organization is in the meaning of \pm Below the tipping point of $\mathrm{zq} 0$, the state of the organization becomes precarious, as does its business success.

As a result, we will get the same leaping system change at the defining parameter A, which is the value of the Altman model.

Looking at a "assembly" disaster, we took an outgoing formula in which the value of the time $t$ was a defining parameter (Figure 3,4$)$ :

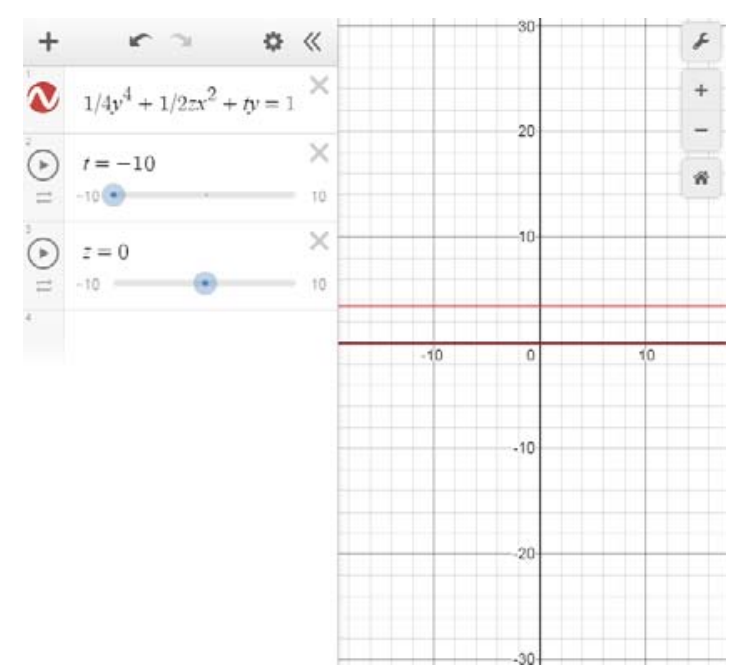

Fig. 3. Behavior $\mathrm{v}$ at $\mathrm{z} \mathrm{q} 0$ and $\mathrm{t}-10$ (the organization's sustainability curve at profitability 0 and time shift $\mathrm{t}$ ). Compiled by the author. 


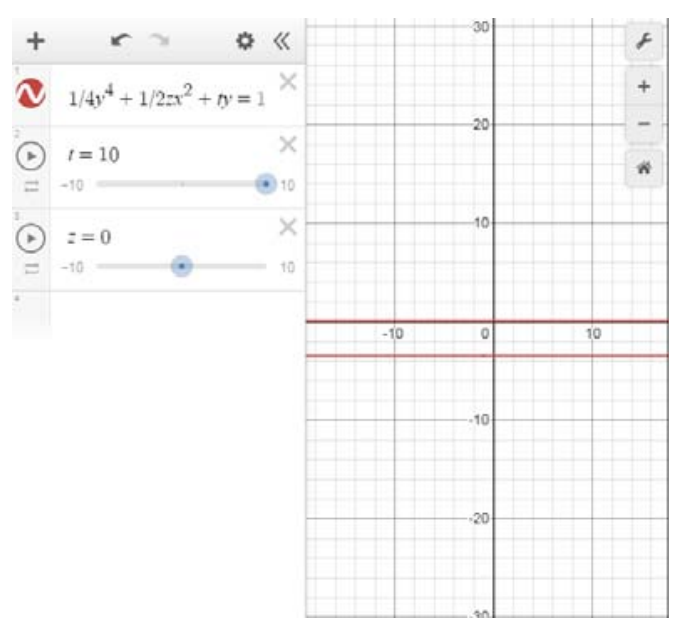

Fig. 4. Behavior v at z q 0 and t q 10 (the organization's sustainability curve at profitability 0 and time shift $\mathrm{t}$ ). Compiled by the author.

When we have a time indicator, we see a shift in straight lines on the graph, which indicates that the effect of the time parameter itself on the behavior of the graph is significant. In this way, we introduce the time factor into the factors influencing the business success of the organization.

We believe that one of the features of time is the fundamental impossibility of representing one moment of time for verification measurements and observations, which makes different authors have different understandings of business success.

We also show the importance of the impact of the temporary factor, which, although fundamentally unclear, but which has the specifics to influence other factors of the organization's activities.

The physical object has exactly one state at any given time. Other states are considered possible, but not existing. And the mathematical model of the same object has all the states. To highlight one state of an object that is implemented, the math uses a time model that looks like a parameter, each value of which is matched by a certain one state. This correspondence is called the process of changing states, and is best researched through the theory of bifurcation.

We believe that by introducing the time factor, it is necessary to identify the priorities that determine business success. We allocate such indicators to socio-environmental and economic values - Altman coefficient, time and number of layoffs in the organization.

$\mathrm{X}$ (Altman's Value - Economic Indicator) - Figure 5.

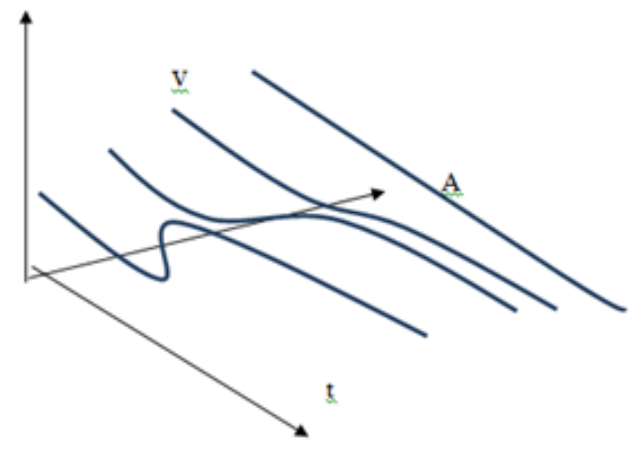

Fig. 5. Graphic interpretation of business success in socio-environmental-economic coordinates. Compiled by the authors. 
This graph shows us that the business success of an organization is determined by the value of the Altman coefficient (economic factor), the number of layoffs (social indicator-A) and time, and it is necessary to take into account at the same time the influence of all values of the Figure 6,7.

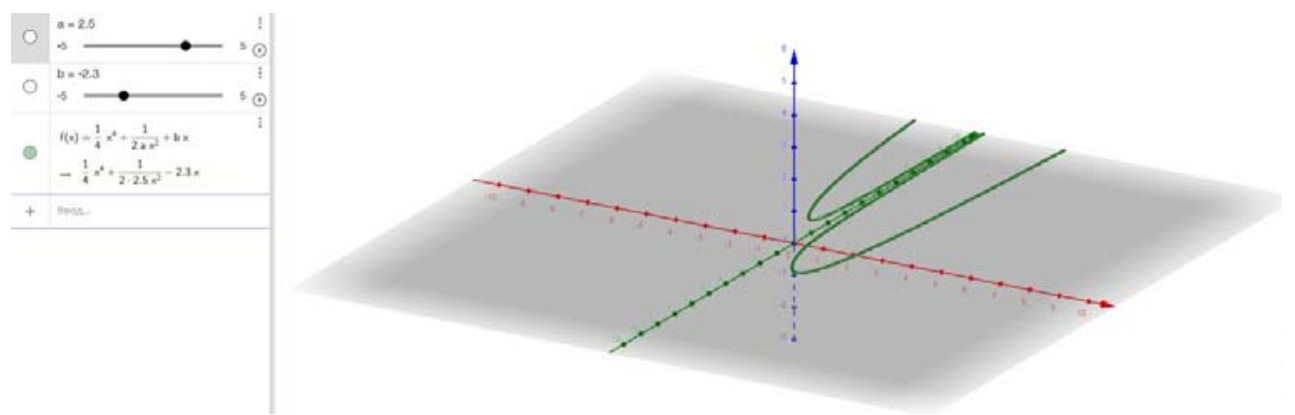

Fig. 6. Function behavior at negative value $b$ (time). Compiled by the authors.

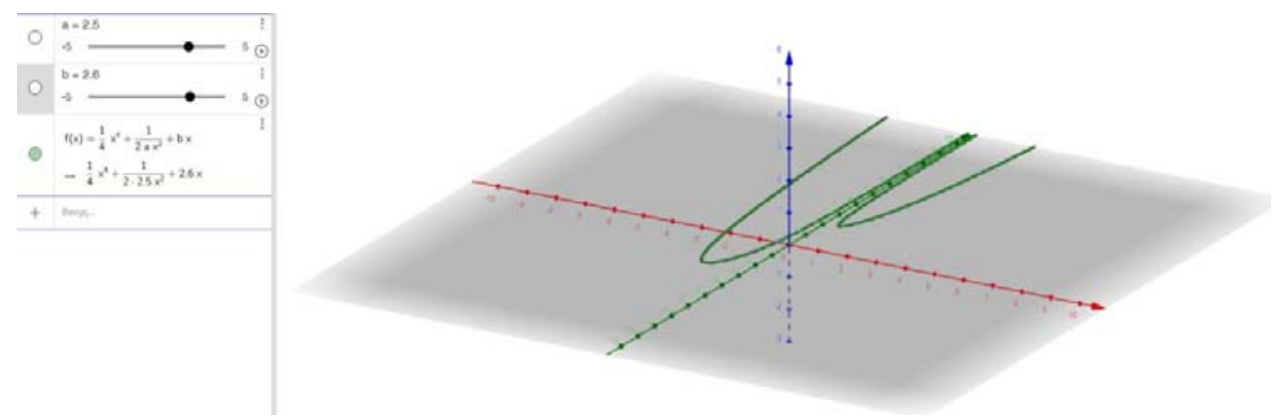

Fig. 7. Function Behavior at Positive Value B (Time). Compiled by the authors.

In the graphs, the green line is time t.The red line is the Altman coefficients.

Summing up, we built a cognitive map of Modern Stone LLC, a manufacturer of building materials in the Chelyabinsk region, consisting of 20 concepts, showed the mutual influence of concepts on each other. Through expert assessments, we have determined the power of factors to influence each other. We determined that Modern Stone LLC was in a state of uncertainty at the beginning. However, by bringing corrections from the cognitive map to Altman's model, we could see that the state of the organization was changing from uncertainty to bankruptcy zone. That is, by calculating the Altmat coefficient without taking into account the influence of the cognitive map, we got a value of 1,201, while taking into account the influence of the map we got a value of 2.1. In this regard, we can draw the first conclusion that Modern Stone LLC was in the zone of uncertainty at the stage of origin. Therefore, it should be noted that there is a difference in calculations. In the first case the organization is in bankruptcy, in the second in uncertainty. In our opinion, this is due to the level of detail of the calculations.

The same can be seen when building a function based on the theory of bifurcation - with a slight change in profitability there is a jump transition from one state to another (graph 1, graph 2). We put the Values of Altman in Equation 27, which is the basis for the study of bifurcation theory, and naturally received different values before and after the substitution of expert values about the power of factors in the cognitive map.

However, when considering the profitability in the winter of the organization for the production of building materials in the Chelyabinsk region of "Modern Stone" llc at zero profitability, the schedule changes dramatically, which shows us some ambivalence when applying the theory of bifurcation, directly dependent on time. 
Note that we show the importance of the influence of time. Thus, when we are operating on the presence of a time indicator, we see a shift in straight lines on the graph, which indicates to us the significance of the influence of the time parameter on the behavior of the graph. In this way, we introduce the time factor into the factors influencing the business success of the organization. We believe that one of the features of time is the fundamental impossibility of re-presenting one moment of time for verification measurements and observations, which makes different authors have different understandings of business success. These findings provide a new assessment of mathematical approaches to studying and evaluating business success, as well as demonstrating the importance of multilateral study of the issue.

Thus, by business success it is necessary to understand a non-physical object, showing the position of the organization in the system of coordinates - X,and, t, where $X$ - the value of the Altman coefficient, and - the number of layoffs of employees, $t$ - time.

\section{Discussion and Conclusion}

We proposed a new approach to determining business success by using cognitive maps and bifurcation theory. In practice, we have found evidence of our theory that cognitive cards influence the business success of an organization, as well as the activities of the organization are influenced by time. Let's pay attention to the charts 6 and 7, which were higher. Look on the Figure 8.

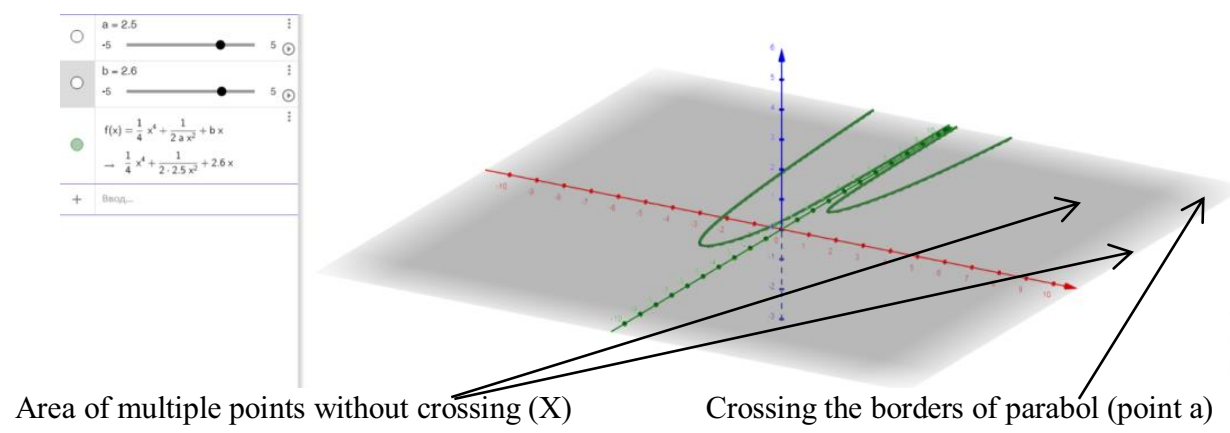

Fig. 8. Function Behavior at Positive Value B (Time). Compiled by the authors.

By examining the time intervals on graphs 6 and 7, we come to a number of definitions of interval topology, which, in our opinion, most fully characterize our additions to the definition and evaluation of business success.

A lot of $\alpha$ (a lot of $\mathrm{x}$, where a point is less than a set of dots) of all points following $\alpha$ is called the future of the $\alpha \alpha \alpha \alpha$ point and is marked with $\alpha \alpha$. i.e. in any $\alpha$ point area, there are points from $\alpha$ and $\alpha$-. If $p, q \in(a, b)$ and $p q$, then $(p, q) \subset(a, b)$ (in other words, business success at each point belongs to itself, but the interval of business success may not belong to the point where it is located).

With this work, we have clarified the concept of business success, defining it with the help of socio-environmental-economic coordinates, but note that the clarification we have found is not a point of business success, but an interval.

This work will complement existing methods in identifying and researching business success in mathematical categories, such as assessing business success through cognitive maps and bifurcation theory. We consider this approach particularly relevant in the run-up to the fourth industrial revolution, which is becoming more complex in markets and globalization in general [1]. 
We built cognitive maps to organize the Chelyabinsk region. We also calculated Altman's values for her. However, by substituting the coefficients obtained during the construction of the cognitive map in the Altman model, we see that the indicators are steadily changing. This is because each organization was considered by us from the position of quantum-relativistic approach - that is, was investigated by financial indicators and in the dynamics of expert assessments. Receiving different values To Altman we see that the organization is in a different position at the same time, that is, manifests wave properties. We conclude that the organization needs to be investigated comprehensively, not just from one side, which we have justified on the calculations [7].

Note also that the study of indicators with the help of cognitive maps is a novelty, and fully with the disclosure of full theoretical aspects previously authors were not used. The same can be noted about the application of the theory of bifurcation, which clearly shows the impact of socio-environmental and economic factors on the organization [10].

Similarly, we can consider any subject of economic activity - a group of companies, region, country, non-profit organizations. The basis for the study of the subject of economic activity, we also offer cognitive maps and socio-environmental-economic indicators, which will be the basis when applying the theory of bifurcation for the study of SED.

\section{References}

1. V. Barkhatov, D. Pletnev, A. Campa, Procedia - Social and Behavioral Sciences 221, 29-38 (2016)

2. Barkhatov, V. I. Large-Sized Enterprises In Russia: An Analysis Of Federal Districts (2019) DOI: 10:24411/1994-2796-2019-10720

3. G.N. Pryakhin, D.A. Trukhanov, J.G. Maltsev, Mathematical and instrumental methods of economics 124 (2019) https://www.elibrary.ru/item.asp?id=41312029

4. G.N. Pryakhin, D.A. Trukhanov, J.G. Maltsev, Azimut of scientific research: economics and management 8.3(28), 243-245 (2019) DOI: 10.26140/anie-2019-0803-0058

5. D. Pletnev, E. Nikolaeva, VIII International Scientific Siberian Transport Forum, 643656 (2020) https://doi.org/10.1007/978-3-030-37919-3_65

6. D. Pletnev, V. Barkhatov, International Symposium in Management SIM2019, 127-136 (2019) https://doi.org/10.1007/978-3-030-44711-3_10

7. E.A. Ponomarenko, Research Methodology For The Assessment Of The Influence Of Organizational Culture Aspects On Project Success (2019) doi 10.17072/1994-99602019-3-495-512

8. N. Ćurčić1, V. Miletić, Factors Important For Achieving The Competitiveness Of Industrial And Agroindustrial Products (2020) doi:10.5937/ekoPolj2003831C

9. M. Nurdin Diah, F. Safrida, Analysis Off Actor Saffecting Business Success Of Micro And Small Enterprises (2018) DOI https://doi.org/10.18551/rjoas.2018-12.15

10. E.A. Strelchenko, High Jewelry Brand Graff: Key Features Of Business Strategy (2019) DOI:10.22394/2079-1690-2019-1-4-143-146

11. E.V. Matuzenko, S.I. Shilenko, J.O. Fedorova, Fundamental research 9-3, 622-627 (2016) DOI: $10.24412 / 2304-6139-2020-10596$

12. A.A. Shamray, Small Business Life Cycle (Liberal Mission Foundation, M., 2010) DOI: 10.29758/2399-6439-2017-10576

13. D.A. Trukhanov, A.A. Yegorova, J.G. Maltsev, A.O. Alreadygov, Herald of Chelyabinsk State University Economic sciences 2(436).68, 219-226 (2020) DOI: 10.24411/1994-2796-2020-10222. 